\title{
FENOLOGIA E PRODUÇÃO DE CULTIVARES AMERICANAS E HÍBRIDAS DE UVAS PARA VINHO, EM JUNDIAI-SP ${ }^{1}$
}

\author{
JOSÉ LUIZ HERNANDES², MÁRIO JOSÉ PEDRO JÚNIOR ${ }^{3}$, \\ ANTONIO ODAIR SANTOS ${ }^{4}$, MARCO ANTONIO TECCHIO ${ }^{5}$
}

RESUMO- O comportamento fenológico e produtivo das cultivares de uvas rústicas para vinho 'Moscatel de Jundiaí', 'Máximo’, 'Madalena', 'Seibel 10096’, 'Isabel’ e 'Niagara Rosada' foi avaliado em vinhedo localizado em Jundiaí (SP), durante os anos agrícolas de 2000/01 a 2002/03. As videiras foram enxertadas em 'IAC 766' e conduzidas em espaldeira, com poda curta de inverno. O delineamento experimental foi o inteiramente casualizado, com parcelas de três plantas e cinco repetições. Foram realizadas avaliações fenológicas semanais a partir da data de poda e, na época da colheita, determinaram-se as variáveis: produção por planta; número e massa dos cachos, e teor de sólidos solúveis. As cultivares 'Seibel 10096', 'Moscatel de Jundiaí’, 'Madalena’ e ‘Máximo’ mostraram-se mais tardias com ciclo de 149 dias em comparação à 'Niagara Rosada', que foi a mais precoce, com ciclo de 135 dias. 'Máximo' e 'Seibel 10096’ apresentaram

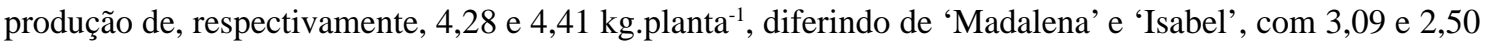
kg.planta ${ }^{-1}$. Para 'Moscatel de Jundiaí’ e 'Niagara Rosada’, foram obtidas produções intermediárias entre 3,0 e 3,5 kg.planta-1 . Para 'Seibel 10096', foi obtido o maior valor de massa do cacho (283,6g), enquanto, para 'Isabel' (96,5g) e 'Madalena' (139,6g), foram obtidos os menores valores. Os maiores valores de teor de sólidos solúveis, acima de 17,0 Brix, foram obtidos na 'Moscatel de Jundiaí', 'Máximo’ e 'Seibel 10096', enquanto 'Isabel’ e 'Niagara Rosada' apresentaram valores inferiores a 15,9 Brix. Dentre as cultivares avaliadas, podem constituir-se em opção para o viticultor a ‘Máximo’ e a 'Seibel 10096’ para vinhos tintos, e 'Moscatel de Jundiaí', para brancos.

Termos para indexação: vitivinicultura, fenologia, sólidos solúveis.

\section{PHENOLOGY AND YIELD OF AMERICAN AND HYBRID GRAPEVINE CULTIVARS IN JUNDIAÍ, STATE OF SÃO PAULO (BRAZIL)}

\begin{abstract}
A field trial was carried out on grapevines grown in Jundiaí, São Paulo state, Brazil, during the growing seasons from 2000/01 to 2002/03. Agronomic and phenological characteristics were evaluated for the following American and hybrid grape cultivars: 'Moscatel de Jundiaí’; 'Máximo’, 'Madalena', 'Seibel 10096', 'Isabel' and 'Niagara Rosada' grafted on 'IAC 766'. The statistical design used was completely randomized, with plots containing three plants and five replicates. Phenological evaluations were weekly taken and measurements of grape yield and soluble solids content were taken at harvest time. The cultivars 'Seibel 10096', 'Moscatel de Jundiaí', 'Madalena’ and 'Máximo’ showed the longest duration cycle with an average of 149 days when compared to 'Niagara Rosada' with 135 days. The values of yield obtained for 'Máximo' and 'Seibel 10096' were respectively, 4.28 and $4.41 \mathrm{~kg}$.plant ${ }^{-1}$ and they were statistically different from 'Madalena' and 'Isabel', respectively, 3.09 and 2.50 kg.plant ${ }^{-1}$. The cultivars 'Moscatel de Jundiaí', and 'Niagara Rosada' showed yields varying from 3.0 to 3.5 kg.plant ${ }^{-1}$. The cultivar 'Seibel 10096' showed the highest value for bunch weight (283.6 g) when compared to 'Isabel' and 'Madalena' with mean values of $96.5 \mathrm{~g}$ and $139.6 \mathrm{~g}$, respectively. The highest values of soluble solids content (higher than $17^{\circ} \mathrm{Brix}$ ) were obtained for 'Moscatel de Jundiaí'; 'Máximo' and 'Seibel 10096'. However, values lower than 15.9³rix were obtained for 'Isabel' and 'Niagara Rosada'. Among the evaluated cultivars, it may constitute an option for the viticulturist 'Máximo' and 'Seibel 10096’ for red wines and 'Moscatel de Jundiaí' for white wines. Index terms: viticulture, enology, phenology, soluble solids.
\end{abstract}

${ }^{1}$ (Trabalho 072-09).Recebido em: 31-03-2009. Aceito para publicação em: 27-11-2009.

${ }^{2}$ Biólogo MS., PqC Centro de Fruticultura, IAC, Jundiaí- SP, Brasil, e-mail: jlhernandes@iac.sp.gov.br

${ }^{3}$ Eng. Agr. Dr., Centro de Ecofisiologia e Biofísica, IAC, Campinas-SP, Brasil, e-mail: mpedro@iac.sp.gov.br Bolsista do CNPQ

${ }^{4}$ Eng. Agr. Dr., Centro de Engenharia e Automação, IAC, Jundiaí-SP, Brasil, e-mail: odairsan@iac.sp.gov.br

${ }^{5}$ Eng. Agr. Dr., Centro de Fruticultura, IAC, Jundiaí-SP, Brasil, e-mail: tecchio@iac.sp.gov.br 


\section{INTRODUÇÃO}

A distribuição da vitivinicultura no Brasil mostra uma preponderância da superfície vitícola no Rio Grande do Sul, com aptidão predominantemente vinícola (Pommer \& Maia, 2003), enquanto a região de Jundiaí, na qual a viticultura tomou vulto a partir do início do século XX (Inglez de Sousa, 1959), tornou-se o principal polo brasileiro produtor de uvas comuns de mesa.

Atualmente, na região leste de São Paulo, de acordo com Protas et al. (2006), as uvas destinadas à elaboração de vinhos representam aproximadamente $0,7 \%$ da produção total, sendo a grande maioria constituída de americanas e híbridas. As cultivares utilizadas pelos viticultores da região são, em sua maioria, provenientes do programa de melhoramento genético do Instituto Agronômico de Campinas, que visava à obtenção de variedades de uvas de vinho, uvas de mesa e porta-enxertos (Ferri \& Pommer, 1995).

Com a intensificação do turismo rural na região produtora de Jundiaí, os produtores de uva de mesa, têm voltado, ainda que de maneira incipiente, porém organizada, à produção de vinho artesanal, principalmente utilizando cultivares americanas. Diante dessa perspectiva de revitalização da vitivinicultura, algumas restrições foram constatadas, dentre as quais, a falta de melhor conhecimento das cultivares de uvas para vinho e seu comportamento nas condições climáticas regionais (Silva et al., 2008).

Em São Paulo, a produção de vinhos está baseada em uvas como 'Isabel', 'Seibel 2', 'Niagara Branca’, ‘Niagara Rosada’ e ‘Máximo’ (Terra et al., 1990). A predominância do cultivo de uvas rústicas e híbridas é devida à preferência dos consumidores locais por vinhos com características destas variedades. Dentre essas cultivares, a 'Niagara Rosada' tem sido avaliada, na região de Jundiaí, principalmente em relação à produção (Terra et al., 1988; Pedro Júnior et al., 2007) e caracterização fenológica (Pedro Júnior et al., 1993). Além da 'Niagara Rosada', outras cultivares de uvas rústicas foram avaliadas em relação à produtividade sobre diferentes portaenxertos, porém em diferentes condições ecológicas do Estado de São Paulo (Terra et al., 1990; Terra et al., 2001). As cultivares 'Máximo’ e ' Sanches', para vinhos tintos, e 'Rainha' e 'IAC 960-12', para brancos, foram avaliadas em Tatuí e Tietê, tendo a cultivar 'Máximo' demonstrado maior estabilidade de produção, com valores de cerca de 3 kg.planta ${ }^{-1}$. Em Monte Alegre do Sul-SP, a 'Máximo' obteve produções que variaram entre 2,8 e 4,5 kg.planta ${ }^{-1}$ em função do porta-enxerto utilizado (Terra et al., 1990).

Na região produtora de Jundiaí (SP), verifica-se uma escassez de informações sobre o comportamento de cultivares de uva para vinho. Com base no exposto, este trabalho teve por finalidade avaliar o comportamento fenológico e produtivo de cultivares de uva rústica para vinho, visando a subsidiar os produtores nas ações de implantação de novos vinhedos, bem como servir de base de comparação para novos estudos de manejo vitivinícola.

\section{MATERIAL E MÉTODOS}

O experimento foi realizado em vinhedo localizado na área experimental do Centro de Fruticultura, do Instituto Agronômico (IAC/APTA/SAA), situado no município de Jundiaí (SP). A área experimental situa-se a $23^{\circ} 17^{\prime} \mathrm{S}$ e $46^{\circ} 09^{\prime} \mathrm{O}$, com altitude de 715 m. O clima da região, segundo Köeppen, é Cfa para as menores altitudes e Cfb para as maiores.

Avaliaram-se as cultivares de uvas para vinho ‘Moscatel de Jundiaí (Jd 930)’; ‘ Máximo (IAC 138-22)'; 'Madalena (IAC 21-14)’; 'Seibel 10096’; 'Isabel' e 'Niagara Rosada', enxertadas sobre o portaenxerto 'IAC 766'. O vinhedo estava com 8 anos de idade, sendo as videiras sustentadas em espaldeira baixa (1,6m), com cordão esporonado unilateral, com as plantas espaçadas em $2 \times 1 \mathrm{~m}$. Realizaram-se podas curtas, com 2 a 3 gemas por esporão, nos ciclos de 2000/01 (poda em 9-8); 2001/02 (poda em 20-7) e 2002/03 (poda em 17-8). Após a poda, utilizou-se Dormex (4\%) para a quebra de dormência das gemas.

Os tratos culturais foram feitos como recomendados para a região, sendo realizadas desbrotas, desponte dos ramos produtivos e desfolhas. O controle de doenças fúngicas foi realizado com a aplicação semanal de fungicidas cúpricos e à base de Mancozeb.

O delineamento experimental foi o inteiramente casualizado, com seis tratamentos (cultivares), parcela experimental de três plantas e quinze repetições (5 parcelas x 3 anos), para minimizar os possíveis efeitos dos anos e permitir a caracterização média das cultivares avaliadas.

Após a poda, foram realizadas, semanalmente, avaliações fenológicas, utilizando-se da escala de notas que variava de 1 (gema dormente) a 17 (colheita), segundo Pedro Júnior et al. (1989). Os subperíodos fenológicos analisados foram: (1-2) poda-brotação; (2-10) brotação-florescimento; (1016) florescimento-início da maturação; (16-17) inicio da maturação-colheita e (1-17) poda-colheita. 
Na colheita, foram avaliadas as variáveis de produção (kg.planta $\left.{ }^{-1}\right)$, número de cachos, massa dos cachos (g) e teor de sólidos solúveis (TSS em ${ }^{\circ}$ Brix). O TSS foi determinado por refratômetro manual, com escala de 0 a $32{ }^{\circ}$ Brix, a partir de amostras compostas por quatro bagas maceradas, sendo uma da parte superior, uma da parte inferior e duas da parte central do cacho.

Os valores médios obtidos das variáveis fenológicas (normalizadas) e fitotécnicas foram submetidos à análise de variância (teste F) e comparação de médias, pelo teste de Tukey (5\% de probabilidade).

\section{RESULTADOS E DISCUSSÃO}

Os valores médios obtidos da duração dos subperíodos fenológicos para diferentes anos agrícolas e cultivares de uva rústica para vinho estão apresentados na Tabela 1.

Foi observado que o subperíodo podabrotação variou em média entre 12 e 25 dias para as diferentes cultivares. 'Niagara Rosada' e 'Isabel' apresentaram a menor duração do subperíodo, isto é, 12 e 14 dias, respectivamente, diferindo estatisticamente dos valores obtidos para 'Madalena' e 'Seibel 10096’, respectivamente, 24 e 25 dias. Ferri (1994) relatou, em avaliação de banco de germoplasma em Jundiaí, valores de 13 a 18 dias para 'Isabel' e de 11 a 21 dias para 'Niagara Rosada’. Também, Pedro Júnior et al. (1993) obtiveram valores entre 16 e 18 dias para este subperíodo, para 'Niagara Rosada’ podada em agosto, na região de Jundiaí. Valores de duração mais longos deste subperíodo (25 dias) foram relatados para 'Niagara Rosada', em Caldas (MG) (Alvarenga et al., 2002).

A duração do subperíodo brotação-florescimento da cultivar 'Niagara Rosada', de 34 dias, diferiu estatisticamente de 'Moscatel de Jundiaí' e 'Seibel 10096', que tiveram duração entre 39 e 41 dias. No caso da 'Niagara Rosada', Pedro Júnior et al. (1993) relataram duração de subperíodo brotaçãoflorescimento da ordem de 40 dias.

Em relação ao subperíodo florescimento-início da maturação, a ‘Máximo’ e a ‘Seibel 10096’ mostraram as menores durações (53 dias), comparadas à 'Isabel' e 'Niagara Rosada', cujas durações foram de 65 a 67 dias. Para 'Niagara Rosada', Alvarenga et al. (2002) observaram, em Caldas(MG), durações de 67 dias, similares aos obtidos neste estudo.

O subperíodo maturação-colheita foi mais longo para a cultivar 'Máximo', com duração de 36 dias, e mais curto para 'Niagara Rosada', com média de 22 dias. Para as cultivares 'Isabel’, 'Seibel 10096’, 'Madalena' e 'Moscatel de Jundiaí' observaram-se valores entre 26 e 30 dias.

O ciclo total da poda à colheita, das diferentes cultivares, apresentou as maiores durações para 'Máximo', 'Seibel 10096’, 'Moscatel de Jundiaí' e 'Madalena', cujos valores variaram de 146 a 149 dias, não diferindo estatisticamente entre si, ao nível de 5\%. A cultivar 'Isabel' apresentou valor médio de duração de 142 dias, e a 'Niagara Rosada’ mostrou o menor ciclo, com cerca de 135 dias.

Os valores de duração do ciclo de 'Isabel' foram semelhantes aos observados por Maia et al. (2002), que relataram para essa cultivar, enxertada sobre 'IAC 766', valores de duração de 143 dias da poda até a colheita, em Campina Verde (MG). Porém, Roberto et al. (2004), avaliando 'Isabel’ no noroeste do Paraná, encontraram valores médios de 127 dias para o ciclo total, provavelmente por serem plantas em primeiro ano de produção.

No caso da 'Niagara Rosada', Ferri (1994), em Jundiaí, observou durações do período podacolheita variando entre 143 e 146 dias, valores semelhantes aos obtidos neste estudo. Também Pedro Júnior et al. (1993), para 'Niagara Rosada', em Jundiaí, relataram valores de duração do ciclo variando entre 150 e 159 dias, em função da época de poda.

A caracterização das principais fases fenológicas é importante para melhor conhecimento da influência das condições climáticas anuais sobre o desenvolvimento da videira e auxiliará na tomada de decisões tanto de manejo do vinhedo ao longo do ciclo, quanto de preparação da vinícola para recepção da matéria-prima, além do que, séries longas e homogêneas de informações cronológicas são valiosas para caracterizar com rigor os anos agrícolas. A experiência demonstra que as diferenças entre zonas de uma mesma região são mais constantes do que se possa imaginar, e o conhecimento comparativo de um setor permite indicar, com grande confiabilidade, a precocidade de toda uma região e, por conseguinte, prever uma boa organização do trabalho, com meses de antecedência (Blouin \& Guimberteau, 2004).

Observa-se, na Figura 1, que a menor duração do ciclo da poda até a colheita, da 'Niagara Rosada' e 'Isabel', deveu-se principalmente ao menor número de dias da poda-brotação e do início da maturação-colheita, que compensaram a fase mais demorada entre o florescimento-início da maturação destas cultivares. Por outro lado, observa-se que as cultivares 'Máximo', 'Seibel 10096', 'Moscatel de Jundiaí' e 'Madalena' apresentaram as maiores durações do ciclo início da maturação-colheita, o que pode ser considerado um fator positivo para cultivares destinadas à produção de vinhos, uma vez 
que os componentes qualitativos das bagas da uva, como os açúcares, ácidos e taninos, entre outros, são produzidos neste período de desenvolvimento da videira (Blouin \& Guimberteau, 2004).

Observou-se influência do ano agrícola na duração do ciclo das cultivares analisadas em função das temperaturas do ar ocorridas durante a época de crescimento. No ano agrícola de 2001/02, com menores valores de temperatura, ocorreram ciclos mais longos, enquanto no ano agrícola de 2002/03, com temperaturas mais elevadas, ocorreu diminuição na duração do ciclo em cerca de 13 dias.

Os valores referentes à caracterização produtiva das cultivares são apresentados na Tabela 2. As cultivares 'Máximo’ e 'Seibel 10096' apresentaram maiores produções, respectivamente, 4,28 e 4,41 kg.planta ${ }^{-1}$, diferindo estatisticamente de 'Madalena' e 'Isabel', que apresentaram produções médias de 3,09 e 2,50 kg.planta-1, respectivamente. Para as cultivares 'Moscatel de Jundiaí', 'Madalena' e 'Niagara Rosada', foram obtidas produções médias, respectivamente, de 3,37; 3,09 e 3,35 kg.planta ${ }^{-1}$, considerando-se os três anos agrícolas. Estes valores de produção são importantes do ponto de vista vitivinícola, pois quando extrapolados ao potencial de produtividade por hectare, chega-se a valores em torno de 20 ton/ha' ${ }^{-1}$ para 'Máximo' e 'Seibel 10096', 15 ton/ha ${ }^{-1}$ para 'Moscatel de Jundiaí’, 'Madalena’ e 'Niagara Rosada’ e de 12,5 ton/ha-1 para 'Isabel', o que permite, principalmente para ‘Máximo' e 'Seibel 10096’, a redução do nível de carga, com vistas à melhoria da qualidade das bagas.

Terra et al. (1990) obtiveram produções médias de 'Máximo' sobre 'IAC 766’ de 2,39 kg.planta-1, em Tietê (SP), e 2,09 kg.planta-1, em Tatuí (SP), sendo que em alguns anos as produções atingiram 3,19 kg.planta-1.

Em relação à 'Isabel', Terra et al. (2001) relataram produções de 2,86 kg.planta-1 ${ }^{-1}$ na região de Mococa (SP), utilizando o porta-enxerto 'IAC 766', em espaldeira. Essa cultivar, que representa $40 \%$ das uvas produzidas no Rio Grande do Sul, conduzida em latada, mostrou produções de 5,1 kg.planta-1 (Rombaldi et al., 2004).

Para a 'Niagara Rosada', cultivar mais utilizada na região de Jundiaí, foi verificada produção média de 3,35 kg.planta-1. Valores semelhantes de produção por planta foram obtidos também por Terra et al. (2003), em Monte Alegre do Sul (3,19 kg), Orlando et al. (2003), em Minas Gerais (3,99 kg), e Pedro Júnior et al. (2006), em Jundiaí (2,98 kg).

$\mathrm{O}$ número de cachos por planta variou entre 14,6 a 27,2, com valores médios, para os anos agrícolas analisados, superiores para a 'Isabel’ $(25,8)$, em comparação com a 'Seibel 10096' (15,7 cachos/ planta). As cultivares 'Máximo', 'Madalena', 'Moscatel de Jundiaí' e 'Niagara Rosada’ apresentaram valores intermediários, variando, em média, de 18,0 a 22,5 cachos por planta.

Em relação à massa de cacho, a cultivar 'Seibel 10096' destacou-se por apresentar valores médios de 283,6g enquanto para a 'Isabel' foram obtidos os menores valores, em média 96,5g por cacho. A cultivar 'Madalena' foi estatisticamente diferente da 'Isabel', com valor médio de 139,6g, que foi inferior aos obtidos para 'Moscatel de Jundiaí', 'Máximo' e 'Niagara Rosada', cujos valores obtidos ficaram entre 184,8 e 195,8 g. Os valores de massa do cacho da cultivar 'Máximo', em Jundiaí, foram superiores aos relatados por Terra et al. (1990), para vinhedos conduzidos em Monte Alegre do Sul, onde obtiveram cerca de $153 \mathrm{~g}$ em plantas enxertadas em 'IAC 572'.

O número de cachos por planta, bem como o tamanho ou massa dos cachos estão diretamente relacionados à produtividade da videira, variável de grande importância para cultivares híbridas e rústicas nas quais altas produtividades são condição fundamental para a viabilidade da produção.

Os valores de teor de sólidos solúveis obtidos para as cultivares de uva de vinho, para a região de Jundiaí, não foram elevados, possivelmente porque o período de maturação ocorre em condições de excesso hídrico e altas temperaturas diurnas e noturnas, além de possíveis limitações genéticas das cultivares. Os maiores valores foram observados para 'Moscatel de Jundiaí', ‘Máximo’ e ‘Seibel 10096’, sendo superiores a $17^{\circ}$ Brix. Apenas para 'Isabel' e 'Niagara Rosada' os valores de teor de sólidos solúveis foram inferiores a $15,9^{\circ}$ Brix. Esses valores são inferiores aos obtidos no Sul do País para 'Isabel' (Rombaldi et al. 2004) e têm-se mostrado insatisfatórios para produção de vinho artesanal na região, necessitando de alterações de manejo para melhoria deste parâmetro de qualidade.

O teor de sólidos solúveis, ou concentração de açúcar nas bagas, é uma variável diretamente relacionada à qualidade do vinho, uma vez que determinará a necessidade ou não de adição de açúcar de cana no processo de vinificação para atingir o teor alcoólico necessário, que, segundo Rizon et al. (1994), deve ser de, no mínimo, $10,5^{\circ} \mathrm{GL}$, que corresponde a um teor de sólidos solúveis na uva, em torno de $21^{\circ}$ Brix. Quanto maior o teor de álcool proveniente do açúcar de cana, pior a qualidade do vinho. O processo de adição de açúcar de cana para corrigir o teor alcoólico dos vinhos, chamado chaptalização, é proibido na grande maioria dos países produtores, mas permitido 
legalmente no Brasil.

Os dados apresentados no presente estudo indicam que as cultivares 'Moscatel de Jundiaí', para vinhos brancos e 'Máximo’ e 'Seibel 10096' para vinhos tintos, mostraram-se promissoras, principalmente para produção de vinhos artesanais. Além disso, 'Máximo’ destaca-se por possuir bagas pequenas, apresentar elevada produção e bom teor de sólidos solúveis. O tamanho das bagas influencia nas variáveis qualitativas do vinho, e bagas pequenas apresentam relação casca/mosto mais elevada que favorece a qualidade, uma vez que é nas cascas que se concentram os componentes que irão determinar a cor e o aroma, principalmente nos vinhos tintos (Rizon et al., 1994).

O potencial destas cultivares pode ainda ser melhorado através de modificações no manejo, como: a mudança no sistema de condução para espaldeira alta (2 a 2,20 m), visando ao aumento da superfície foliar exposta (SFE), como forma de assegurar, ao mesmo tempo, maior interceptação e distribuição dos raios solares, com incidência direta no aumento da atividade fotossintética das folhas e consequente aumento no acúmulo de açúcares e outros constituintes das bagas (Regina et al., 2006a); o controle do nível de carga, que afeta principalmente a maturação das bagas, visando a melhor equilíbrio entre produtividade e qualidade (Muñoz et al., 2002), e o deslocamento da época de poda, visando a coincidir a colheita com períodos de condições climáticas mais adequadas à maturação da uva para produção de vinho (Rosier, 2006 e Regina et al., 2006b). Tais possibilidades abrem espaço para diversos outros estudos sobre a produção de uvas para vinho na região de Jundiaí.

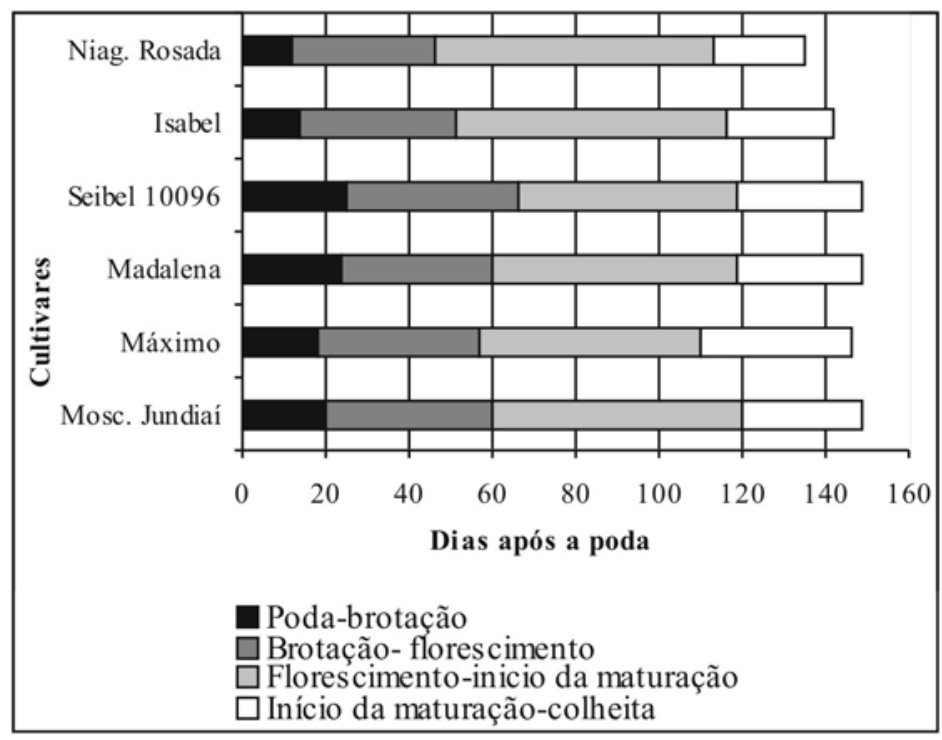

FIGURA 1 - Duração média dos diferentes subperíodos fenológicos de cultivares de uvas rústicas e híbridas para vinho, em Jundiaí (SP). 
TABELA 1 - Duração, em dias, dos diferentes subperíodos fenológicos de híbridos de uva para vinho nos anos agrícolas de 2000/01 (poda em 09-08), 2001/02 (poda em 20-07) e 2002/03 (poda em 17-08), em Jundiaí (SP).

\begin{tabular}{|c|c|c|c|c|c|c|c|}
\hline \multirow[b]{2}{*}{ Subperíodo } & \multirow[b]{2}{*}{$\begin{array}{c}\text { Ano } \\
\text { agrícola }\end{array}$} & \multicolumn{6}{|c|}{ Cultivar } \\
\hline & & $\begin{array}{l}\text { 'Moscatel } \\
\text { de Jundiaí' }\end{array}$ & 'Máximo' & 'Madalena' & $\begin{array}{l}\text { 'Seibel } \\
\text { 10096' }\end{array}$ & 'Isabel' & $\begin{array}{l}\text { 'Niagara } \\
\text { Rosada' }\end{array}$ \\
\hline \multirow{4}{*}{ Poda-brotação } & $2000 / 01$ & 14 & 14 & 20 & 23 & 14 & 14 \\
\hline & 2001/02 & 23 & 19 & 27 & 26 & 11 & 11 \\
\hline & $2002 / 03$ & 22 & 20 & 26 & 26 & 17 & 11 \\
\hline & Média & $20 b$ & $18 b$ & $24 a$ & $25 a$ & $14 c$ & $12 c$ \\
\hline \multirow{4}{*}{$\begin{array}{c}\text { Brotação- } \\
\text { florescimento }\end{array}$} & $2000 / 01$ & 43 & 45 & 38 & 40 & 39 & 41 \\
\hline & 2001/02 & 41 & 35 & 30 & 45 & 30 & 30 \\
\hline & $2002 / 03$ & 36 & 38 & 39 & 39 & 43 & 30 \\
\hline & Média & $40 a$ & 39b & $36 b, c$ & $41 a$ & 37a,b,c & $34 c$ \\
\hline \multirow{4}{*}{$\begin{array}{l}\text { Florescimento- } \\
\text { início } \\
\text { da maturação }\end{array}$} & $2000 / 01$ & 61 & 46 & 61 & 57 & 71 & 65 \\
\hline & 2001/02 & 60 & 63 & 63 & 51 & 70 & 70 \\
\hline & $2002 / 03$ & 59 & 49 & 52 & 50 & 54 & 67 \\
\hline & Média & $60 \mathrm{~b}$ & $53 c$ & $59 b$ & $53 c$ & $65 a$ & $67 a$ \\
\hline \multirow{4}{*}{$\begin{array}{c}\text { Início da } \\
\text { maturação- } \\
\text { colheita }\end{array}$} & $2000 / 01$ & 34 & 46 & 31 & 31 & 23 & 17 \\
\hline & $2001 / 02$ & 33 & 32 & 38 & 35 & 30 & 26 \\
\hline & $2002 / 03$ & 21 & 29 & 21 & 25 & 24 & 24 \\
\hline & Média & $29 b$ & $36 \mathbf{a}$ & $30 \mathbf{b}$ & $30 \mathbf{b}$ & $26 c$ & 22c \\
\hline \multirow{4}{*}{ Poda-colheita } & $2000 / 01$ & 152 & 152 & 150 & 151 & 146 & 136 \\
\hline & 2001/02 & 157 & 150 & 158 & 157 & 142 & 136 \\
\hline & $2002 / 03$ & 138 & 136 & 138 & 140 & 138 & 132 \\
\hline & Média & $149 a$ & $146 a$ & 149a & 149a & 142 a, b & $135 c$ \\
\hline
\end{tabular}

*Médias seguidas da mesma letra na horizontal não diferem entre si, ao nível de 5\%, pelo teste de Tukey.

TABELA 2 - Médias de produção (kg.planta-1), massa dos cachos (g); número de cachos e teor de sólidos solúveis ( ${ }^{\circ}$ Brix) para híbridos de uva para vinho, em diferentes anos agrícolas, para Jundiaí (SP).

\begin{tabular}{|c|c|c|c|c|c|c|c|}
\hline \multirow[t]{2}{*}{ Variável } & \multirow{2}{*}{$\begin{array}{c}\text { Ano } \\
\text { Agrícola }\end{array}$} & \multicolumn{6}{|c|}{ Cultivar } \\
\hline & & $\begin{array}{l}\text { 'Moscatel } \\
\text { de Jundiaí' }\end{array}$ & 'Máximo' & 'Madalena' & $\begin{array}{l}\text { 'Seibel } \\
\text { 10096' }\end{array}$ & ‘Isabel’' & $\begin{array}{l}\text { 'Niagara } \\
\text { Rosada' }\end{array}$ \\
\hline \multirow{4}{*}{$\begin{array}{c}\text { Produção } \\
\text { (kg.planta-1) }^{-1} \text { ) }\end{array}$} & 2000/01 & 3,44 & 4,16 & 2,78 & 4,64 & 2,50 & 3,22 \\
\hline & $2001 / 02$ & 3,42 & 4,62 & 3,62 & 3,76 & 2,68 & 3,86 \\
\hline & $2002 / 03$ & 3,26 & 4,06 & 2,88 & 4,82 & 2,32 & 2,96 \\
\hline & Média & 3,37b & $4,28 a$ & 3,09b,c & $4,41 a$ & $2,50 \mathrm{c}$ & $3,35 b$ \\
\hline \multirow{4}{*}{$\begin{array}{l}\text { Número de } \\
\text { cachos por } \\
\text { planta }\end{array}$} & $2000 / 01$ & 18,2 & 18,6 & 25,8 & 14,6 & 27,2 & 17,0 \\
\hline & $2001 / 02$ & 19,6 & 26,2 & 22,4 & 15,4 & 27,0 & 22,4 \\
\hline & $2002 / 03$ & 17,2 & 22,8 & 19,4 & 17,0 & 23,2 & 14,6 \\
\hline & Média & $18,3 b, c$ & 22,5a,b & 22,4a,b & $15,7 \mathrm{c}$ & $25,8 a$ & $18,0 b, c$ \\
\hline \multirow{4}{*}{$\begin{array}{r}\text { Massa do } \\
\text { cacho (g) }\end{array}$} & $2000 / 01$ & 189,6 & 234,8 & 107,4 & 320,8 & 91,2 & 187,6 \\
\hline & $2001 / 02$ & 176,0 & 175,0 & 163,0 & 243,2 & 99,0 & 174,0 \\
\hline & $2002 / 03$ & 188,8 & 177,6 & 148,4 & 286,8 & 99,4 & 202,2 \\
\hline & Média & $184,8 b$ & $195,8 b$ & $139,6 c$ & $283,6 a$ & $96,5 d$ & $187,9 b$ \\
\hline Teor de & $2000 / 01$ & 16,8 & 16,8 & 16,6 & 16,4 & 15,8 & 14,4 \\
\hline sólidos & $2001 / 02$ & 18,0 & 17,6 & 15,8 & 18,2 & 16,0 & 15,6 \\
\hline solúveis & 2002/03 & 16,7 & 16,6 & 16,1 & 17,0 & 16,0 & 15,3 \\
\hline ( ${ }^{\circ}$ Brix) & Média & $17,2 a$ & $17,0 a$ & $16,2 a, b$ & $17,2 a$ & 15,9a,b & $15,1 b$ \\
\hline
\end{tabular}

*Médias seguidas da mesma letra na horizontal não diferem entre si, ao nível de 5\%, pelo teste de Tukey. 


\section{CONCLUSÕES}

1-As cultivares 'Moscatel de Jundiaí', 'Máximo’, ‘Madalena', 'Seibel 10096’ e ‘Isabel’ apresentaram ciclo poda-colheita mais longo que 'Niagara Rosada’, sendo ‘Máximo’ e 'Seibel 10096’ as mais produtivas, enquanto 'Isabel', a menos produtiva, no período analisado.

2-A cultivar 'Isabel' foi a que apresentou maior número de cachos e menor valor de massa dos cachos, enquanto ‘Seibel 10096' mostrou os maiores valores de massa do cacho.

3-A combinação das variáveis produtividade e potencial de concentração de açúcar das cultivares 'Máximo’, 'Moscatel de Jundiaí’ e 'Seibel 10096’ indicam estas como boas alternativas para os produtores de uva de vinho da região de Jundiaí.

\section{REFERÊNCIAS}

ALVARENGA, A. A.; REGINA, M. A.; FRÁGUAS, J. S.; CHALFUN, N. N.; SILVA, A. L. Influência de porta-enxerto sobre o crescimento e produção da cultivar de videira 'Niagara Rosada' (Vitis labrusca L. x Vitis vinifera L.) em condições de solo ácido. Ciência e Agrotecnologia, Lavras, p.1459-1464, 2002. Edição Especial

BLOUIN, J.; GUIMBERTEAU, G. Maduración y madurez de la uva. 4. ed.,Madrid: Mundi-Prensa, 2004. 151p

FERRI, C. P. Caracterização agronômica e fenológica de cultivares e clones de videira (Vitis spp) mantidos no Instituto Agronômico. 1994. 89 f. Dissertação (Mestrado em Agronomia, Área Concentração Fitotecnia) - Escola Superior de Agricultura Luiz de Queiroz, Universidade de São Paulo, Piracicaba, 1994.

FERRI, C. P.; POMMER, C. V. Quarenta e oito anos de melhoramento da videira em São Paulo, Brasil. Scientia Agrícola, Piracicaba, v.52, n.1, p.107-122, 1995.

INGLEZ DE SOUSA, J. S. Origens de vinhedo paulista. Jundiaí: Prefeitura Municipal de Jundiaí, Jundiaí, 1959. 319p.

MAIA, J. D. G.; CAMARGO, U. A.; NACHTIGAL, J. C. Avaliação da cv. 'Isabel' em três sistemas de condução e em dois porta-enxertos para a produção de suco em região tropical. In: CONGRESSO BRA-
SILEIRO DE FRUTICULTURA, 17., 2002, Belém. Anais... Belém: SBF, 2002. CD-ROM.

MUÑOZ, R.; PEREZ, J.; PSZCZOLKOWSKI, Ph.; BORDEU, E. Influencia del nível de carga y microclima sobre la composición y calidad de bayas, mosto y vino de Cabernet Sauvignon. Ciencia y Investigación Agraria, Santiago, v.29, n.2, p. 115125, 2002.

ORLANDO, T. G. S.; REGINA, M. A.; SOARES, A. M.; CHALFUN, N. N.; SOUZA, C. M.; FREITAS, G. F.; TOYOTA, M. Caracterização agronômica de cultivares de videira (Vitis labrusca L.) em diferentes sistemas de condução. Ciência e Agrotecnologia, Lavras, p.1460-1469, 2003. Edição Especial

PEDRO JUNIOR, M. J.; HERNANDES, J. L.; TECCHIO, M. A.; PEZZOPANE, J. R. M. Influência do sistema de condução no microclima, produtividade e qualidade de cachos da videira 'Niagara Rosada' em Jundiaí (SP). Revista Brasileira de Fruticultura, Jaboticabal, v. 29, p. 313-317, 2007.

PEDRO JUNIOR, M. J.; PEZZOPANE, J. R. M.; HERNANDES, J. L.; ABRAMIDES, P. L. G. Sistemas de condução da videira 'Niagara Rosada': efeitos na transmissão de radiação solar e na produtividade. Revista Brasileira de Agrometeorologia, Santa Maria, v.14, p.1-9, 2006.

PEDRO JUNIOR, M. J.; RIBEIRO, I. J. A.; POMMER, C. V.; MARTINS, F. P. Caracterização de estádios fenológicos da videira 'Niagara Rosada'. In: CONGRESSO BRASILEIRO DE FRUTICULTURA, 10., 1989, Fortaleza. Anais... Fortaleza: Sociedade Brasileira de Fruticultura, 1989. p. 453-456.

PEDRO JUNIOR, M. J.; SENTELHAS, P. C.; POMMER, C. V.; MARTINS, F. P.; GALLO, P. B.; SANTOS, R. R.; BOVI, V.; SABINO, J. C. Caracterização fenológica da videira 'Niagara Rosada' em diferentes regiões paulistas. Bragantia, Campinas, v.52, n.2, p. 153-160, 1993.

POMMER, C. V.; MAIA, M. L. Introdução. In: POMMER, C. V. Uva tecnologia de produção, póscolheita, mercado. Porto Alegre: Cinco Continentes, 2003. p.11-35.

PROTAS, J. F. S.; CAMARGO, U. A.; MELLO, L. M. R. Vitivinicultura brasileira: regiões tradicionais e polos emergentes. Informe Agropecuário, Belo Horizonte, v.27, n.234, p.7-15, 2006. 
REGINA, M. A.; FRÁGUAS, J. C.; ALVARENGA, A. A.; SOUZA, C. R.; AMORIM, D. A.; MOTA, R. V.; FÁVERO, A. C. Implantação e manejo do vinhedo para produção de vinhos de qualidade. Informe Agropecuário, Belo Horizonte, v.27, n.234, p.16-31, 2006a.

REGINA, M. A.; AMORIM, D. A.; FÁVERO, A. C.; MOTA, R. V.; RODRIGUES, D. J. Novos polos vitícolas para produção de vinhos finos em Minas Gerais. Informe Agropecuário, Belo Horizonte, v.27, n.234, p.111-118, 2006b.

ROBERTO, S. R.; YAMASHITA, F.; SATO, A. J.; BRENNER, E. A.; SANTOS, C. E.; GENTA, W. Fenologia e soma térmica (graus-dia) para a videira 'Isabel' (Vitis labrusca) cultivada no noroeste do Paraná. Semina, Londrina, v.25, n.2, p.165-172, 2004.

RIZON, L. A.; ZANUZ, M. C.; MANFREDINI, S. Como elaborar vinho de qualidade na pequena propriedade. Bento Gonçalves: EMBRAPACNPUV, 1994. 36p. (Documentos, 12)

ROMBALDI, C. V.; BERGAMASQUI, M.; LUCCHETA, L.; ZANUZO, M.; SILVA, J. A. Produtividade e qualidade de uva, c.v. 'Isabel', em dois sistemas de produção. Revista Brasileira de Fruticultura, Jaboticabal, v.26, n.1, p.89-91, 2004.

ROSIER. J. P. Vinhos de altitude: característica e potencial na produção de vinhos finos brasileiros. Informe Agropecuário, Belo Horizonte, v.27, n.234, p.105-110, 2006.

SILVA, P. R.; OJIMA, A. L. R.; FRANCISCO, V. L. F. S.; VERDI, A. R.; BAPTISTELLA, C.S. L. Diagnóstico produtivo, tecnológico e gerencial da vitivinicultura no Estado de São Paulo. Informações Econômicas, São Paulo, v. 38, n. 4, 2008.
TERRA, M. M.; PIRES, E. J. P.; PETTINELI JÚNIOR, A.; POMMER, C. V.; SABINO, J. C.; PASSOS, R. S.; COELHO, S. M. B. M.; SILVA, A. C. P.; RIBEIRO, I. J. A. Produtividade de cultivares IAC de uvas para vinho como produtores diretos e sobre diferentes porta-enxertos. Bragantia, Campinas, n.49, n.2, p.345-362, 1990.

TERRA, M. M.; PIRES, E. J. P.; POMMER, C. V.; PASSOS, I. R. S.; MARTINS, F. P.; RIBEIRO, I. J. A. Comportamento de porta-enxertos para o cultivar de uva de mesa 'Niagara Rosada' em Jundiaí - SP. In: CONGRESSO BRASILEIRO DE FRUTICULTURA, 9., 1987, Campinas. Anais... Campinas: Sociedade Brasileira de Fruticultura, 1988. v.2, p.721-725.

TERRA, M. M.; PIRES, E. J. P.; COELHO, S. M. B.; PASSOS, I. R. S.; POMMER, C. V.; SILVA, A. C. P.; RIBEIRO, I. J. A. Porta-enxertos para o cultivar Máximo IAC 138-22 de uvas de vinho em Monte Alegre do Sul, SP. Bragantia, Campinas, v.49, n.2, p.363-368, 1990.

TERRA, M. M. ; PIRES, E. J. P.; POMMER, C. V.; BOTELHO, R. V. Produtividade da cultivar de uva de mesa 'Niagara Rosada' sobre diferentes portaenxertos, em Monte Alegre do Sul - SP. Revista Brasileira de Fruticultura, Jaboticabal, v. 25, n. 3, p. 549-551, 2003.

TERRA, M. M.; POMMER, C. V.; PIRES, E. J. P.; RIBEIRO, I.J.A.; GALLO, P.B.; PASSOS, I.R.S. Produtividade de cultivares de uvas para suco sobre diferentes porta-enxertos IAC em Mococa-SP. Revista Brasileira de Fruticultura, Jaboticabal, v.23, n.2, p.382-386. 2001. 